\title{
HOW ACCURATELY PHYSICIANS MEASURE BLOOD PRESSURE- AN OBSERVATIONAL STUDY IN ENAM MEDICAL COLLEGE AND HOSPITAL, SAVAR
}

\author{
RUKHSANA PARVIN ${ }^{1}$, MD. NAZMUL HAQUE ${ }^{2}$, MD IMRAN ALI ${ }^{3}$, MOHAMMAD MAHBUBUL ALAM $^{3}$, AKM \\ RAFIQUEUDDIN ${ }^{4}$
}

\begin{abstract}
Objective: The key to blood Pressure (BP) control is good BP measurement. If BP measurements are not done accurately and reliably, there is a potential for great harm and great cost. Measuring blood pressure is a routine procedure but errors are frequently committed during recording. The aim of the study was to look at the prevalent practices in the institute regarding BP recording.

Methods and Materials: This study was conducted in the department of Medicine, Surgery and Gynaecology and Obstetrics in Enam Medical College, Savar. This is an prospective observational study performed amongst 50 doctors in EMCH. Doctors in each three departments were observed by one observer in each department during the act of BP recording. The observer was well versed with the guidelines issued by British Hypertension Society (BHS) and the deviations from the standard set of guidelines were noted. The errors were defined as deviations from these guidelines. The results were recorded as percentage of doctors committing these errors and analysis of results was done manually with percentage and number.

Results: In our study, 100\% doctors used aneroid type sphygmomanometer. Ninety percent of apparatus were without error. Ninety six percent of the BP cuff was of standard size. Twenty two percent of the doctors did not let the patient rest before recording BP. None of them recorded BP in both arms. In outpatient setting, 70\% recorded blood pressure in sitting position and $30 \%$ in supine position. In 44\% patients where BP was recorded in sitting position BP apparatus was below the level of heart and $60 \%$ did not have their arm supported. Eighty four percent did not use palpatory method before checking the BP by auscultation. Sixty percent lowered the BP at a rate of more than $2 \mathrm{~mm} / \mathrm{s}$. Seventy six percent recorded BP only once and $75 \%$ of the rest reinflated the cuff without completely deflating and allowing rest before a second reading was obtained.

Conclusion: Although the assessment of $B P$ is the most cost-effective procedure in medicine, it is rarely performed according to guidelines. Efforts should be taken to improve the practice of BP measurement which would have a major impact on the health of the population
\end{abstract}

Keywords: Aneroid, palpatory method, auscultatory method.

\section{Introduction}

The blood pressure (BP) measurement is one of the commonly performed procedures by the doctors. Raised blood pressure (hypertension) is a common condition that does not have specific clinical manifestations until target organ damage develops ${ }^{1}$ Routine screening of all the patients, especially high risk patients, is the only way of detecting hypertension early and initiate treatment before target organ damage becomes evident ${ }^{2}$ Accurate measurement of $\mathrm{BP}$ is importance for labeling a patient as hypertensive. Consistently underestimating the BP by $5 \mathrm{~mm} \mathrm{Hg}$ could result in two-thirds of hypertensive patients being missed and over estimating it by 5 $\mathrm{mm} \mathrm{Hg}$ could more than double the number of patients being diagnosed as hypertensive. ${ }^{3}$ Missing the diagnosis in a hypertensive patient could result in significant morbidity and mortality due to lack of treatment. Over diagnosis results in inappropriate labeling and treatment of healthy individuals. Most of us are aware of the exact methodology of recording of BP, yet most of us commit errors frequently resulting in erroneous high or low recording.

The measurement of BP in clinical practice is done by a century old Riva-Rocci/Korotkoff technique. The accurate measurement is dependent on the accurate transmission and interpretation of a signal (Korotkoff

1. Assistant Professor, Dept of Medicine, Enam Medical College

2. Assistant Registrar,Dept of Medicine, Enam Medical College

3. Internee doctor ,Dept of Surgery, Enam Medical College

4. Professor and Head of the Department of Medicine, Enam Medical College

Bangladesh J Medicine 2011; 22 : 12-16 
sound or pulse wave) from a subject via a device (the sphygmomanometer) to an observer ${ }^{4}$ Errors in measurement can occur at each point but the commonest fallible component is the observer. 4

Despite the clear guidelines on BP measurement technique, there seems to be large inter-observer variations, both among nursing staff and physicians as well as between the two groups. In an article by Graves and Ships in the American Journal of Hypertension, the authors are of opinion that 'physicians do not measure BP well, and even if they do, the usefulness of their BP measurements is significantly compromised by the white coat effect. ${ }^{5}$ The general belief amongst the researchers is that physicians dealing with diagnosis and treatment of hypertension do not follow the international society guidelines. ${ }^{6}$ In a study by Perloff et al ${ }^{7}$, it was found that nursing staff abided by $40 \%$ of the recommended procedures while medicine teachers, physicians and residents abided by approximately $70 \% .{ }^{8}$ The wide gaps in the basic theoretic and practical knowledge seem to be common among interns and first-year family practice residents resulting in erroneous measurements. 9 In an interesting observational study, carried out at the Westminster Medical School in London, showed that $33 \%$ out of 80 doctors in training grades/junior hospital doctors, acknowledged no formal education on how to measure BP, a finding confirmed further by the poor accuracy in BP measurement displayed by one-third of the study group. 10 There has not been many study done in Bangladesh regarding objective performance of blood pressure recording according to guideline. This study was done to observe the practice of blood pressure recording of physicians in tertiary care hospital and to identify the pitfall.

Objectives: Our objective was to notice the common errors committed during routine blood pressure recording by the residents and consultants

\section{Methods and Materials}

A prospective, observational study was performed amongst 50 doctors (10 consultants and 40 residents). The consultants belonged to the department of medicine, surgery and gynaecology and the residents included interns, house physicians and indoor medical officer. The study was conducted over a period of 2 months. A single observer from each department were trained uniformly regarding blood pressure measurement according to British Hypertension Society (BHS) and tested clinically by principal investigator for accuracy and consistency. A single observer in each department observed the enrolled subjects during the act of $\mathrm{BP}$ recording without any one of them being aware of the fact that they were being observed. The common errors committed were noted in a performance after having observed them but the recording physicians were not informed regarding the study procedure of observer. Some participants were observed again to note the practices that had been missed during the first observation. The observer recorded the finding retrospectively in a structured case report form.

The errors were defined as variations from the standard set of instructions issued by British Hypertension Society( BHS) ${ }^{11}$ This variation from the standard guidelines were further analyzed and recorded as percentage of doctors committing these individual errors. At the end of the study the erring doctors were apprised of the results of the study and were told about the standard guidelines.

\section{Results}

Fifty study subjects were observed in different departments of Enam Medical College Hospital (EMCH) for their blood pressure recording techniques. In this study, $100 \%$ doctors used aneroid type sphygmomanometer. $90 \%$ of apparatus were without error. $96 \%$ of the BP cuff was of standard size. $22 \%$ of the doctors did not let the patient rest before recording BP. None of them recorded BP in both arms.

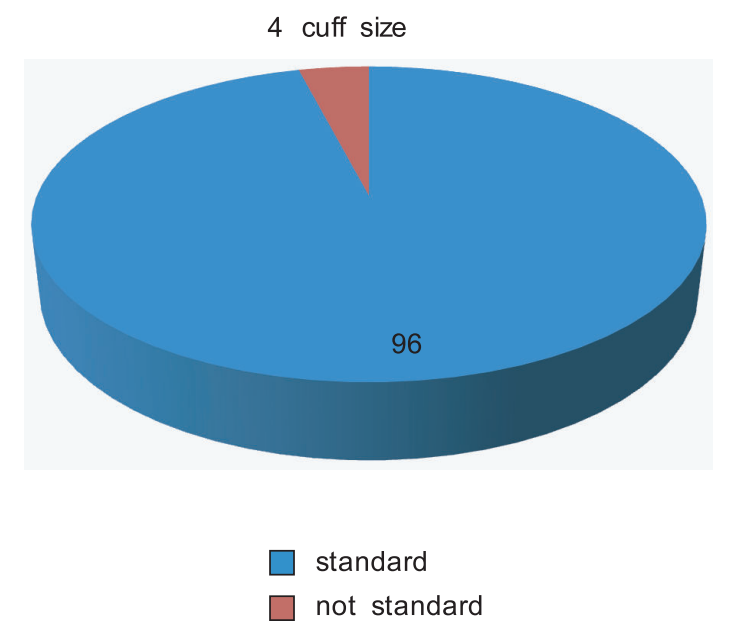

In outpatient setting, $70 \%$ recorded blood pressure in sitting position and $30 \%$ in supine position. In $44 \%$ patients where BP was recorded in sitting position BP apparatus was below the level of heart and $60 \%$ did not have their arm supported. $84 \%$ did not use palpatory method for noticing systolic BP and $58 \%$ did not raise pressure $20-30 \mathrm{~mm} \mathrm{Hg}$ above the systolic level before checking the BP by auscultation.60\% lowered the $\mathrm{BP}$ at a rate of more than $2 \mathrm{~mm} / \mathrm{sec}$. $76 \%$ recorded BP only once and $75 \%$ 
of the rest reinflated the cuff without completely deflating and allowing rest before a second reading was obtained.

\section{Discussion}

The blood pressure in all the individuals varies considerably throughout the day. A variety of activities affects the BP and causes it to increase. Simple activities of daily routine like eating, dressing, commuting to work, talking on telephone and attending a meeting raises systolic BP by an average 10-20 mm $\mathrm{Hg}$ and diastolic BP by $8-15 \mathrm{~mm} \mathrm{Hg.}^{3}$ Numerous studies have proven time and again that the various exogenous factors also interfere with the

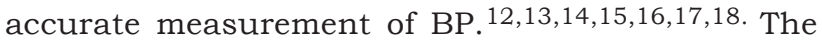
important factors being talking, exposure to cold, ingestion of alcohol and medications especially antihypertensive drugs. ${ }^{12,13,14}$ Errors during the process of BP measurement also contribute to the erroneous reading.

There are only three sources of errors while BP is being recorded. These are observer bias, faulty equipment and failure to standardize techniques of measurement ${ }^{19}$. While it may not be possible to do anything for observer bias but following a standardized technique and using a good equipment may help to reduce the error rate to a great extent.

It is well known that mercury instruments provide the most accurate records and are the preferred instrument in hospital settings .20 Aneroid sphygmomanometers are increasingly used due to ease of handling ${ }^{21}$ but are a source of error if not maintained properly ${ }^{22}$.Since the majority recording apparatus in our hospital are aneroid based, so 100\% of our recordings were made on them.

The defective apparatus may give a false high or low $\mathrm{BP}$ reading. Similarly, the BP in the dominant hand is usually higher ${ }^{1}$.Failure to record these facts may lead to differences in the subsequent BP recordings. Unfortunately this fact is commonly ignored and not recorded, as was evident in our study.

It has been shown in a recent study that both the bell and the diaphragm give equal results when used for office measurement of BP. ${ }^{23}$ still the diaphragm is preferred in clinical practice, as was in our study. The reason for this lies in it being easier to secure with the fingers of one hand and also that it covers a larger area. ${ }^{4}$

In a survey of 114 doctors conducted by McKay et al $97 \%$ doctors used inappropriate cuff size. ${ }^{24}$ It indicates that it is a common mistake made by most of the doctors. It is known that if the cuff is too small as in the case of a fat patient the systolic BP will be recorded falsely low by up to $8 \mathrm{~mm} \mathrm{Hg}$ and diastolic $\mathrm{BP}$ will be recorded high by up to $8 \mathrm{~mm} \mathrm{Hg.}{ }^{17} \mathrm{Our}$ findings are not different from these observations. The failure to remove the clothing further adds to the arm circumference, hence erroneous recording. A number of studies have shown that measurement of $\mathrm{BP}$ in obese and large muscular arms requires adjustments. Monograms for adjusting BP recording in the obese are inadequate. The most important factor is choosing the correct cuff width-arm circumference $(\mathrm{CW} / \mathrm{AC})$ ratio. Such action reduces the intersubject variability of BP measurement in clinical settings. ${ }^{25}$

It is known that a number of activities of daily living raise the $\mathrm{BP}^{3}$ and a period of rest before measuring $\mathrm{BP}$ may return it to normal level. Failure to do so may result in falsely high BP recording. Still $70 \%$ of our study group doctors did not wait and let the patient rest for some time before recording BP in the OPD. In a study by McKay et al. this figure was $97 \% .{ }^{24}$ None of our study group doctors recorded BP in both arms, which is much more than $77 \%$ reported in the literature. ${ }^{22}$

It is well established that if the BP is only measured in the supine position the systolic BP may increase by $3 \mathrm{~mm} \mathrm{Hg}$ and the diastolic $\mathrm{BP}$ will be recorded lower by $3-5 \mathrm{~mm} \mathrm{Hg} .{ }^{15,26}$ It would be worthwhile to record $\mathrm{BP}$ in both supine and sitting position if possible or at least the position in which the BP is recorded should be mentioned in the records. This would be helpful in follow-up visits by the patient. Unfortunately this fact is taught in the clinics but not followed by majority of us while recording BP, especially in the outpatient department.

If the position of the arm is either above or below the heart level the BP may be recorded false high or low. For every $10 \mathrm{~cm}$ above or below the heart level the systolic BP decreases (if above) by $8 \mathrm{~mm} \mathrm{Hg}$ and increases (if below). ${ }^{15}$ Similar changes are seen in the diastolic BP with change in the position of arm in relation to the heart level. ${ }^{15}$ If the arm is not supported the systolic and diastolic pressures will be recorded high by $2 \mathrm{~mm} \mathrm{Hg.}{ }^{15}$ Our study showed that this fact is commonly forgotten during BP recording in the outpatient department.

About $60 \%$ of our study group doctors did not use palpatory method for noticing systolic BP initially and $70 \%$ did not raise pressure $30-40 \mathrm{~mm} \mathrm{Hg}$ above the systolic level before checking the BP by auscultation. McKay et al. in their study noted similar figures, where the number of such doctors was $61 \% .^{24}$ 
About $60 \%$ in our study group deflated the cuff at a rate of more than $2 \mathrm{~mm} / \mathrm{s}$ which is little variationto $82 \%$ in another study. ${ }^{24}$ Also $76 \%$ in our study group recorded $\mathrm{BP}$ only once and $75 \%$ of the rest reinflated the cuff without completely deflating and allowing rest before a second reading was obtained. This may further increase the incidence of erroneous recording in clinical practice. In one study by Jamieson et al. it was observed that the first systolic BP was on an average 3-4 $\mathrm{mm} \mathrm{Hg}$ higher while the diastolic BP was not different when recorded twice. ${ }^{26}$ Complete deflation of the cuff and allowing a few minutes rest between two consecutive measurements may circumvent this problem, however, this is not routinely done. The authors of this study have suggested an alternative, that taking two measurements and recording the average would help in reducing the errors, when the BP exceeds 155/90 mm Hg. ${ }^{26}$

There is tendency by physicians to expect either a high or low BP. This results in rounding off the systolic and diastolic BP to the nearest 5-10 mm Hg, which may result in erroneous high or low BP recording. ${ }^{18}$ A British study carried out in 18 practices and 67 GP offices showed digit bias in systolic and diastolic readings to the nearest $10 \mathrm{~mm} \mathrm{Hg.}{ }^{27}$ Also $60 \%$ of the doctors in our study group had a digit preference to the nearest $5-10 \mathrm{~mm} \mathrm{Hg}$. Both under estimation or over estimation of $\mathrm{BP}$, due to this bias, could have enormous reflection on the sheer numbers of the patients either missed or over diagnosed. ${ }^{3}$

The most recent recommendations of AHA suggest that the auscultatory technique with a trained observer and mercury sphygmomanometer to be the method of choice for measurement of BP. Proper training of observers, positioning of the patient, and selection of appropriate cuff size are all essential. ${ }^{20}$ However, training can reduce, but not abolish, these inaccuracies. Taking multiple BP measurements before making clinical decisions can limit the effect of these inaccuracies. ${ }^{28}$

Reevs points out that the efficient practitioner can reserve the proper method for $10-20 \%$ of patients who have known or newly detected elevated BP, cardiovascular damage, other risk factors or are receiving antihypertensive therapy. ${ }^{29}$ This would go a long way in preventing the errors in patients where it matters the most.

\section{Conclusion}

Accurate measurement of the BP is very important in the clinical setting. It is a vital parameter to access and modify cardiovascular risk factors. Very commonly errors are committed during these simple procedures and efforts should be made to minimize them by following the international guidelines. This study looks at the practices prevalent in a teaching hospital and proves that accurate measurement of BP is not difficult provided we know the exact methodology and follow it too. The tendency to create shortcuts is likely to result in erroneous high or low recording. We can correct our mistakes only if we are made aware of them.

\section{References}

1. McAlister FA, Straus SE. Measurement of blood pressure: an evidence based review. BMJ 2001;322:908-11.

2. Litenberg BA. Practice guidelines revisited: screening for hypertension. Ann Intern Med 1995; $122: 937-9$

3. Campbell NR, McKay DW. Accurate blood pressure measurement: why does it matter? Can Med Assoc J 1999;161:277-8.

4. Beevers G, Lip GY, O'Brien E. Conventional sphygmomanometry: technique of auscultatory blood pressure measurement. BMJ 2001;322:1043-7. 5.Graves JW, Sheps SG. Does evidence-based medicine suggest that physicians should not be measuring blood pressure in the hypertensive patient? Am J Hypertens 2004;17:354-60.

6. Vancheri F, Alletto M, Sidoti P. Does this patient have hypertension? Different methodologies in the measurement of arterial pressure. Recenti Prog Med 2003;94:106-9. [Article in Italian]

7. Perloff D, Grim C, Flack J, Frohlich ED, Hill M, McDonald M. Human blood pressure determination by sphygmomanometry. Circulation 1993;88:24607 .

8. Veiga EV, Nogueira MS, Carnio EC, Marques S, Lavrador MA, Souza LA, et al. Assessment of the techniques of blood pressure measurement by health professionals. Arq Bras Cardiol 2003;80:89-93.

9. McKay DW, Raju MK, Campbell NR. Assessment of blood pressure measurement techniques. Med Educ 1992;26:208-12.

10. Feher M, Harris-St John K, Lant A. Blood pressure measurement by junior hospital doctors - a gap in medical education. Health Trends 1992;24:59-61

11. The British Hypertension Society. Blood pressure measurement CD ROM. London. BMJ books 1998

12. Le Pailleur C, Helft G, Landais P, Montgermont P. The effect of talking, reading and silence on the "White coat" phenomenon in hypertensive patients. Am J hypertens 1998;11:203-7.

13. Scriven AJ, Brown MJ, Murphy MB, Dollery CT. Changes in blood pressure and plasma catacholamines caused by tyramine and cold exposure. J Cardiovasc Pharmacol 1984;6:954-60. 
14. Potter JF, Watson RD, Skan W, Beever DG. The pressor and metabolic effects of alcohol in normotensive subjects. Hypertension 1986;8:62531 .

15. Neeta RT, Smiths P, Lenders JW, Thein T. Does it matter whether blood pressure measurement are taken with subjects sitting or supine? J Hypertens 1998;16:263-8.

16. Wall manning HJ, Pauline JM. Effect of arm position and support on blood pressure reading. J Clin Hypertens 1987;3:624-30.

17. Russel AE, Wing LM, Smith SA, Aylward PE, Ritchie RJ. Optimal size of cuff bladder for indirect measurement of arterial pressure in adults. J Hypertens 1989;7:607-13. 18.Neufeld PD, Jhonson DL. Observer error in blood pressure measurement. Can Med Asso J 1986;135:633-7.

19. Baily RH, Bauer JH. A review of common errors in the indirect measurement of blood pressure. Arch Intern Med 1993;153:2741-8

20. Pickering TG, Hall JE, Appel LJ, Falkner BE, Graves $\mathrm{J}$, Hill MN, et al. Recommendations for blood pressure measurement in humans and experimental animals: part 1: blood pressure measurement in humans: a statement for professionals from the subcommittee of professional and public education of the american heart association council on high blood pressure research. Circulation 2005;111:697716.
21. Décio MJ, Geraldo Pierin AM, Ines L, Fernando N. Devices and Techniques for Blood Pressure Measurement and Criteria for Hypertension Adopted by Brazilian Physicians. Explorat Study Arq Bras Cardiol 2002;1:79

22. Canzanello VJ, Jensen PL, Schwartz GL. Are aneroid sphygmomanometers accurate in hospital settings. Arch Intern Med 2001;161:729-31.

23. Kantola I, Vesalainen R, Kangassalo K, Kariluoto A. Bell or diaphragm in the measurement of blood pressure? J Hypertens 2005;23:499-503.

24. McKay DW, Campbell NR, Parab LS, Chokalingam A, Fodor JG. Clinical assessment of blood pressure. J Hum Hypertens 1990;4:639-45.

25. Prineas RJ. Measurement of blood pressure in the obese. Ann Epidemiol 1991;1:321-36.

26. Jamieson MJ, Webster J, Philips S, Jeffers TA, Scott AK, Robb OJ, et al. The measurement of blood pressure: sitting or supine, once or twice? J Hypertens 1990;8:635-40. 27.Ali S, Rouse A. Practice audits: reliability of sphygmomanometers and blood pressure recording bias. J Hum Hypertens 2002;16:359-61

28. Kay LE. Accuracy of blood pressure measurement in the family practice center. J Am Board Fam Pract. 1998; 11:252-8.

29. Reevs RA. Does this patient have hypertension? How to measure blood pressure. JAMA 1995; 273:1211-8. 